\title{
A cautionary tale of undetected hyperlipidaemia: implications for coronary artery bypass grafting
}

\author{
Rossitza Naoumova, B Keogh, K Taylor, Gilbert R Thompson
}

A 54 year old man was referred to the lipid clinic at Hammersmith Hospital. In 1984 he had been investigated in a hospital in London because of exertional chest pain of increasing frequency. Within a month he was admitted to a second hospital with acute and extensive myocardial infarction. Angiography, performed in a third hospital, showed triple vessel disease and he underwent coronary artery bypass grafting (CABG) with four saphenous vein grafts. He remained reasonably well until 1991 when he was admitted to a fourth hospital with a second myocardial infarction. A subsequent angiogram at a fifth hospital showed impaired left ventricular function and occlusion of three of his four vein grafts. A few months later positron emission tomography was performed in a sixth hospital which showed an anteroapical myocardial infarct and reversible inferolateral ischaemia.

Though this patient had been investigated in six major hospitals during the past 9 years there is no record of his serum cholesterol ever having been measured until 1993 when he asked this of his general practitioner. The result was $10.6 \mathrm{mmol} / 1$ and he was then referred to our lipid clinic.

DNA analysis showed that the patient had familial defective apolipoprotein $\mathbf{B}_{100}(\mathrm{FDB})$, an inherited condition characterised by impaired binding of low density lipoprotein (LDL) caused by an amino acid substitution in the receptor binding domain of apolipoprotein B; in affected individuals this results in hypercholesterolaemia with a raised LDL cholesterol and premature atherosclerosis. ${ }^{1}$ In people with FDB the clinical presentation and response to treatment are often indistinguishable from familial hypercholesterolaemia.

This unfortunate example of repeated failure to detect hyperlipidaemia both before and after CABG raises two important issues.

\footnotetext{
MRC Lipoprotein Team and Department of Surgery, Hammersmith Hospital, London R Naoumova B Keogh K Taylor G R Thompson Correspondence to: Dr G R Thompson MRC Lipoprotein Team, Hammersmith Hospital, Ducane Road, London W12 OHS.
} long-term angiographic follow up of 132 grafts known to be patent 6-12 months after CABG showed that $38 \%$ were unchanged at $10-12$ years, $32 \%$ had changes suggestive of
Evidence that hyperlipidaemia adversely A postmortem study of 99 vein grafts from normal and hyperlipidaemic patients dying within 5 years after CABG showed that vein atherosclerosis, and $30 \%$ had occluded. ${ }^{3}$ Patients with lesions or occlusion of their grafts had significantly higher concentrations of total cholesterol, triglyceride, and LDL apolipoprotein B, and significantly lower concentrations of high density lipoprotein (HDL) cholesterol than those without lesions.

In the Cholesterol Lowering Atherosclerosis Study (CLAS) the effect on the progression of disease in native vessels and vein grafts of diet plus $30 \mathrm{~g}$ colestipol and $4 \mathrm{~g}$ nicotinic acid daily was compared with diet plus placebo. ${ }^{45}$ Angiograms were obtained after two years in 162 of 188 non-smoking men who entered the study (CLAS I) and again in 103 subjects after four years (CLAS II). In patients treated for 2 or 4 years the combination of diet, colestipol, and nicotinic acid resulted in a $34-36 \%$ greater reduction in LDL cholesterol and $35 \%$ greater increase in HDL cholesterol than in those treated with diet and placebo. Angiographic findings showed that the rate of appearance of new lesions was significantly reduced in the treated patients both in native vessels (14\% drug treated $v 40 \%$ placebo) and bypass grafts ( $16 \%$ drug treated $v 38 \%$ placebo).

The beneficial effect of lipid lowering drugs in preventing lesions was evident both in patients with cholesterol concentrations of $4.8-6.2 \mathrm{mmol} / 1$ and in those with concentrations above $6.2 \mathrm{mmol} / \mathrm{l}$. These findings sug gest that even slight increases in serum cholesterol promote the occurrence of late occlusion of vein grafts and that intensive lipid lowering treatment helps to counteract this tendency.

\section{Guidelines for intervention and target concentrations for LDL cholesterol after CABG}

In 1993 The British Hyperlipidaemia Association published its guidelines for the treatment of hyperlipidaemia. ${ }^{6}$ The highest priority was accorded to patients with existing CHD and those who had had CABG. In this category lipid lowering drugs are recommended if, despite diet, the total cholesterol concentration remains above $5.2 \mathrm{mmol} / \mathrm{l}$ or LDL cholesterol is above $3.4 \mathrm{mmol} / 1$ or both The recommended target concentration for LDL cholesterol in such patients is $<3.4 \mathrm{mmol} / \mathrm{l}$. In the United States the recommended target concentration for LDL cholesterol $(\leqslant 2.6 \mathrm{mmol} / \mathrm{l})$ is even lower. ${ }^{7}$

Despite these guidelines the management 
of hyperlipidaemia after CABG seems inadequate according to a recent report of a retrospective audit carried out in 100 consecutive Welsh patients. ${ }^{8}$ There was no record that serum lipids had been measured in 17 and in a further five lipids had been measured but the results were not in the case notes; lipid values were included in less than half of all the discharge summaries. Of the 41 patients with a serum cholesterol above the median $(6.7 \mathrm{mmol} / \mathrm{l})$ only $12(27 \%)$ were referred to a dietitian and eight (19\%) were prescribed lipid lowering drugs. These workers concluded that few CABG patients were managed appropriately.

We therefore propose that all patients admitted for CABG should have their lipid profile checked preoperatively; all patients with total cholesterol $>5.2 \mathrm{mmol} / 1$ or LDL cholesterol $>3.4 \mathrm{mmol} / 1$ should be given dietetic advice and have their lipid concentrations checked again at 3 months after operation; those who remain above these values should be treated with an appropriate lipid lowering drug. We hope that this will slow the rising rate of re-do procedures, which in 1989 and 1991 accounted for $2 \cdot 4 \%$ and $3 \cdot 8 \%$ of all CABGs done in Britain (UK Cardiac Surgical Register, Society of Cardiothoracic Surgeons of Great Britain and Ireland). Currently in our unit the re-do rate is $11 \%$ compared with just under $14 \%$ in the Cleveland Clinic in 1985, despite the fact that one third of their original grafts came from the internal mammary artery. ${ }^{9}$

It seems appropriate for us to conclude by quoting from a recent editorial by Roberts: "Thus, because secondary prevention is in the hands of cardiologists and because cholesterol lowering has proven benefit after atherosclerotic events, cardiologists must increase their knowledge of and use of low-fat, low-cholesterol diets and lipid-lowering agents". ${ }^{10}$

Additional support for this view can be gleaned from the recent data reported by Law et al which suggest that a $20 \%$ reduction in serum cholesterol by lipid lowering drugs would halve the mortality from coronary heart disease of middle aged people. ${ }^{11}$

1 Myant NB. Familial defective apolipoprotein B-100: a review, including some comparisons with familial hypercholesterolaemia. Atherosclerosis 1993;104:1-18.

2 Lie JT, Lawrie GM, Morris GC. Aortocoronary bypass saphenous vein graft atherosclerosis. Anatomic study of 99 vein grafts from normal and hyperlipoproteinemic 99 vein grafts from normal and hyperlipoproteinemic patients up to 75

3 Campeau L, Enjalbert $M$, Lesperance J, Vaislic C, Grondin CM, Bourassa MG. Atherosclerosis and late closure of aortocoronary saphenous vein grafts: sequential angiographic studies at 2 weeks, 1 year, 5 to 7 years, and 10 to 12 years after surgery. Circulation 1983; 68(Suppl II): 1-7.

4 Blankenhorn DH, Nessim SA, Johnson RL, Sanmarco ME, Azen SP, Cashin-Hemphill L. Beneficial effects of combined colestipol-niacin therapy on coronary atherosclerosis and coronary venous bypass grafts. $\mathscr{f} A M A$ 1987;257:3233-40.

5 Cashin-Hemphill L, Mack WJ, Pogoda JM, Sanmarco ME, Azen SP, Blankenhorn DH. Beneficial effects of colestipol and niacin on coronary atherosclerosis. A 4colestipol and niacin on coronary athero

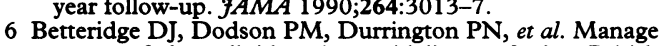
ment of hyperlipidaemia: guidelines of the British Hyperlipidaemia Association. Postgrad Med F 1993;69: 359-69.

7 Expert Panel on Detection, Evaluation and Treatment of High Blood Cholesterol in Adults. Summary of the Second Report of the National Cholesterol Education Program (NCEP) Expert Panel on detection, evaluation, and treatment of high blood cholesterol in adults (Adult Treatment Panel II). $\mathcal{F} A M A$ 1993;269:3015-23.

8 Buchalter MB, Northridge DB, Shandall A, Rees A. Inadequate management of hyperlipidaemia following coronary bypass surgery [abstr]. Atherosclerosis 1993;103: 300 .

9 Cosgrove DM, Gill GC, Gibson C, Taylor PC. Predictors of reoperation after myocardial revascularization. of reoperation after myocardial revasc

10 Roberts WC. Getting cardiologists interested in lipids. Am f Cardiol 1993;72:744-6.

11 Law MR, Wald NJ, Thompson SG. By how much and how quickly does reduction in serum cholesterol concentration lower risk of ischaemic heart disease? $\mathrm{Br}$ Med $\mathfrak{f} 1994 ; 308: 367-73$. 